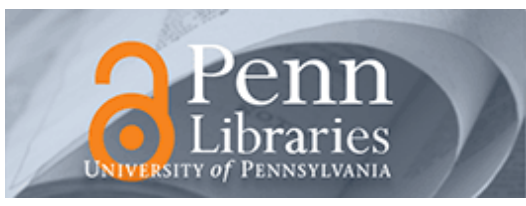

University of Pennsylvania ScholarlyCommons

Wharton Pension Research Council Working

Papers

Wharton Pension Research Council

9-1-2011

\title{
Optimal Financial Literacy and Saving for Retirement
}

Annamaria Lusardi

The George Washington University, alusardi@gwu.edu

Pierre-Carl Michaud

Université du Québec à Montréal and RAND, Pierre-Carl_Michaud@rand.org

Olivia S. Mitchell

The Wharton School, University of Pennsylvania, mitchelo@wharton.upenn.edu

Follow this and additional works at: https://repository.upenn.edu/prc_papers

Part of the Economics Commons

Lusardi, Annamaria; Michaud, Pierre-Carl; and Mitchell, Olivia S., "Optimal Financial Literacy and Saving for Retirement" (2011). Wharton Pension Research Council Working Papers. 184.

https://repository.upenn.edu/prc_papers/184

This paper is posted at ScholarlyCommons. https://repository.upenn.edu/prc_papers/184

For more information, please contact repository@pobox.upenn.edu. 


\title{
Optimal Financial Literacy and Saving for Retirement
}

\begin{abstract}
Recent studies show that financial literacy is strongly positively related to household wealth, but there is also substantial cross-sectional variation in both financial literacy and wealth levels. To explore these patterns, we develop a calibrated stochastic life cycle model which features endogeneous financial literacy accumulation. Our model generates substantial wealth inequality, over and above what standard lifecycle models produce. This is due to the fact that higher earners typically have more hump-shaped labor income profiles and lower retirement benefits which, when interacted with the precautionary saving motive, boosts their need for private wealth accumulation and thus financial literacy. We show that the fraction of the population which is rationally "financially ignorant" depends on the level of labor income uncertainty as well as the generosity of the retirement system.
\end{abstract}

\section{Disciplines}

Economics 


\title{
Optimal Financial Literacy and Saving for Retirement
}

\author{
Annamaria Lusardi, Pierre-Carl Michaud, and Olivia S. Mitchell
}

September 2011

\author{
PRC WP2011-20 \\ Pension Research Council Working Paper \\ Pension Research Council \\ The Wharton School, University of Pennsylvania \\ 3620 Locust Walk, 3000 SH-DH \\ Philadelphia, PA 19104-6302 \\ Tel: 215.898.7620 Fax: 215.573.3418 \\ Email:prc@wharton.upenn.edu \\ http://www.pensionresearchcouncil.org
}

The research reported herein was performed pursuant to a grant from the U.S. Social Security Administration (SSA) funded as part of the Financial Literacy Research Consortium. The authors also acknowledge support provided by the Pension Research Council and Boettner Center at the Wharton School of the University of Pennsylvania, and the RAND Corporation. Michaud acknowledges additional support from the Fond Québécois de Recherche sur la Société et la Culture (FQRSC - \# 145848). We also thank Hugh Hoikwang Kim and Yong Yu for excellent research assistance and we acknowledge the use of the RAND grid computing server to perform our calculations. We thank Audrey Brown for editorial assistance. The opinions and conclusions expressed herein are solely those of the authors and do not represent the opinions or policy of (C)2011 Lusardi, Michaud, and Mitchell. All rights reserved. All findings, interpretations, opinions and conclusions of this paper represent the views of the authors and not those of the Wharton School or the Pension Research Council, SSA, any agency of the Federal Government, or any other institution with which the authors are affiliated. (c) 2011 Pension Research Council of the Wharton School of the University of Pennsylvania. All rights reserved. 


\title{
Optimal Financial Literacy and Saving for Retirement
}

\begin{abstract}
$\underline{\text { Abstract }}$
Recent studies show that financial literacy is strongly positively related to household wealth, but there is also substantial cross-sectional variation in both financial literacy and wealth levels. To explore these patterns, we develop a calibrated stochastic life cycle model which features endogeneous financial literacy accumulation. Our model generates substantial wealth inequality, over and above what standard lifecycle models produce. This is due to the fact that higher earners typically have more hump-shaped labor income profiles and lower retirement benefits which, when interacted with the precautionary saving motive, boosts their need for private wealth accumulation and thus financial literacy. We show that the fraction of the population which is rationally "financially ignorant" depends on the level of labor income uncertainty as well as the generosity of the retirement system.
\end{abstract}

\section{Annamaria Lusardi}

The George Washington University School of Business

alusardi@gwu.edu

Pierre-Carl Michaud

Université du Québec à Montréal and RAND

Pierre-Carl_Michaud@rand.org

Olivia S. Mitchell

Pension Research Council

mitchelo@wharton.upenn.edu 


\section{Introduction}

Wealth levels have been shown to vary considerably over the life cycle and across the population of workers on the verge of retirement. ${ }^{1}$ There is also much dispersion in observed levels of consumer financial sophistication, ${ }^{2}$ and this heterogeneity in financial literacy is positively associated with retirement wealth. ${ }^{3}$ Accordingly, analysts and policymakers interested in retirement system reforms seek to understand what drives these correlations, particularly in an environment where consumers are increasingly required to save for their own retirement. ${ }^{4}$

A handful of prior studies suggests that financial literacy itself is an endogenous variable and that individuals can increase their human capital by investing in financial literacy. ${ }^{5}$ Yet these analyses have not devised an explicit multiperiod theoretical model that can be used to generate cross-sectional differences in wealth-to-income profiles, which is necessary to assess which types of consumers would benefit the most by early investment in financial literacy and sophisticated investment products. The mechanism we propose is that financial literacy enables individuals to better allocate resources over the life cycle. Accordingly, our model explores two important questions: 1) What forces shape financial literacy accumulation over the life cycle?, and 2) How much of the life cycle and cross-sectional variation in wealth might be attributable to differences in financial literacy?

Extending the life cycle model to include financial literacy is useful and indeed imperative for three reasons. First, many consumers appear not to "know" as much as economists often assume in theoretical models. ${ }^{6}$ Accordingly, specifying how literacy is acquired in a life cycle setting should be of keen interest to those seeking to explain wealth dispersion. Second, existing economic models of saving often have a difficult time explaining several stylized facts without appealing to exogenous preference differences or heterogeneity in large fixed

\footnotetext{
${ }^{1}$ See Venti and Wise (2000) and Moore and Mitchell (2000).

${ }^{2}$ See Lusardi and Mitchell (2007b, 2009) and Lusardi, Mitchell and Curto (2010).

${ }^{3}$ See Lusardi and Mitchell (2007a); Behrman, Mitchell, Soo and Bravo (2011); and Van Rooij, Lusardi and Alessie (2011).

${ }^{4}$ See for instance Poterba, Venti and Wise (2009).

${ }^{5}$ See for instance Delavande, Rohwedder, and Willis (2009) and Jappelli and Padula (2011).

${ }^{6}$ For data on this point see Lusardi and Mitchell (2007a, 2011) and Lusardi, Mitchell and Curto (2010).
} 
costs for investing in financial products. ${ }^{7}$ For this reason, economists have not been able to readily explain why a significant fraction of the population reaches retirement with little or no wealth, without assuming either that some subset of consumers is extremely impatient, that they face high replacement rates from government programs and pensions, and other reasons. In this vein, Venti and Wise (2000) show that permanent income differences and chance alone can explain only $30-40 \%$ of observed differences in retirement wealth, implying that other factors should be taken into account. Third, those seeking to replicate observed heterogeneity in wealth across education and permanent income groups have invoked a range of factors including means-testing programs (Hubbard, Skinner and Zeldes, 1994) and impatience in the form of hyperbolic discounting (Angeletos, Laibson, Repetto, Tobacman, and Weinberg, 2001). Still others assume that consumers use rule-of-thumb in saving decisions (Campbell and Mankiw, 1989). In contrast, our analysis builds on Yitzhaki's (1987) work showing that expected returns from financial products differ accross income groups. Accordingly, this paper asks how such differences in returns can arise from endogeneous accumulation of financial literacy.

In what follows, we build and calibrate a stochastic life cycle utility maximization model featuring uncertainty in income, capital market returns, and medical expenditures, and we include an endogenous literacy accumulation process and a sophisticated saving technology. In the model, financial literacy allows consumers to potentially raise the rate of return earned on financial assets, and it also permits them to use more sophisticated financial products. Individuals who wish to transfer resources over time by saving will benefit the most from financial literacy. Moreover, because of how the U.S. social insurance system works, more educated individuals have the most to gain from investing in financial literacy. As a result, allowing for endogenous financial literacy accumulation allows for an amplification of differences in accumulated retirement wealth. Thus our approach departs from traditional saving/consumption models ${ }^{8}$ in that it allows for a choice of a saving technology with returns and costs that depend on each consumer's level of financial literacy. The fact that returns

\footnotetext{
${ }^{7}$ See Cagetti (2003) and Huang and Caliendo (2009).

${ }^{8}$ See Gourinchas and Parker (2002); Cagetti (2003); and Sholz, Seshadri and Khitrakun (2006).
} 
depend on the consumer's level of financial literacy can also be viewed as an extension of models in the portfolio choice literature (e.g. Cocco, Gomes, and Maenhout, 2005) where returns are exogeneous and the consumer only decides how much he will invest in risky assets.

The rest of the paper is structured as follows: Section 2 briefly describes empirical evidence on the lifecycle path of assets, consumers' use of financial products, and financial literacy accumulation by education group. In Section 3, we present our model. Section 4 outlines model calibration, and Section 5 presents our simulation results. A conclusion and discussion appears in Section 6.

\section{$2 \quad$ Life Cycle Wealth and Financial Literacy}

\subsection{The Evolution of Income and Assets by Education}

The simplest life cycle consumption theory posits that consumers save so as to transfer resources to life stages where the marginal utility of consumption is highest. Given concavity of the utility function, consumers will seek to transfer resources from periods of their lives where they earn substantial income, to periods where they earn less. To illustrate typical household income profiles over the lifecycle, Figure 1 plots median net household income by education groups, constructed from the Panel Study of Income Dynamics (PSID). ${ }^{9}$ These income paths are estimated separately for workers prior to age 65 and retirees age $65+$; education groups refer to household heads having completed less than a high-school education, high-school graduates, and those with at least some college. We focus on white males throughout the paper to keep our sample as homogeneous as possible. We also drop individuals with business assets. ${ }^{10}$ [Figure 1 here]

Our evidence, consistent with other studies (e.g. Campbell and Viceira, 2002), indicates that household income for this cohort is hump-shaped over the lifecycle. It also rises at a

\footnotetext{
${ }^{9}$ These data are extracted for PSID respondents born 1935-1945.

${ }^{10}$ Hurst, Kennickell, Lusardi, and Torralba (2010) show that including those with business assets tends to skew the interpretation of saving motives for the general population because of the large amount of wealth they hold and the volatility of their income.
} 
faster rate for the college-educated than for the less-educated. All groups' incomes slowly decrease from the mid-50's to retirement. Income falls sharply on retirement, reflecting the fact that social security and pension benefit amounts are generally lower than labor earnings. Old-age benefit replacement rates are relatively higher for the less-educated groups, due to the progressivity of public safety net programs, so better-educated consumers see their incomes fall relatively more. Thereafter, net household income declines somewhat for all groups, probably because of changes in household composition (e.g. loss of a spouse).

In Figure 2, we trace life cycle paths of median net worth (bank accounts, stocks, IRAs, mutual funds, bonds, net real estate, minus debt) for these same individuals. ${ }^{11}$ For the typical household, net assets grow steadily up to the mid-60s and then flatten or decline after that age. Again, there are sharp differences by educational attainment, with the median college-educated household having more than $\$ 335,000$ in net financial and housing assets at age 65 . By contrast, the median household with less than a high-school education has less than $\$ 100,000$ at the same age.

[Figure 2 here]

In the simplest version of the life cycle model, individuals optimally consume only a portion of their lifetime incomes each period, borrowing in some periods, and saving in others. A key prediction from this framework is that the life cycle path of assets normalized by lifetime income should be the same across groups. As noted by Hubbard, Skinner, and Zeldes (1994), the simple life cycle model for higher earners will simply be a scaled-up version of the lower earners' profile, so it cannot explain observed wealth heterogeneity. Another reason that people save is for precautionary reasons: when income is uncertain and borrowing is difficult, this raises the possibility that a consumer might have a very high marginal utility of consumption in the future, when income is low. When the utility function is concave and exhibits prudence (Kimball, 1990), such a consumer will want to save more in anticipation of this possibility. While precautionary saving can explain some of the heterogeneity we observe in the data, this still falls short of explaining the many

\footnotetext{
${ }^{11}$ For a description of PSID wealth measures and a comparison with the Survey of Consumer Finances, see Juster, Stafford, and Smith (1999).
} 
differences we observe even among those facing similar uncertain incomes.

Still another explanation for why the less-educated fail to save is offered by Hubbard, Skinner, and Zeldes (1994), who point out that the U.S. social insurance system insures consumers with limited resources against bad states of the world. That is, means-tested and redistributive transfer programs such as the Social Security, Medicaid, and Supplemental Security Income programs provide an explicit consumption floor in the event that households face poverty in old age. In turn, this consumption floor dampens consumers' precautionary saving motives, particularly when they are rather likely to become eligible for such benefits. Accordingly, this helps explain why the less-educated save little. Yet it does not rationalize wealth inequality in the upper half of the income distribution, where the consumption floor is unlikely to be reached. Finally, some authors resort to differences in preferences to explain differences in wealth accumulation. For example, Cagetti (2003) uses high rates of time preference and low rates of risk aversion, and he concludes that this combination leads to low amounts of precautionary wealth among less-educated and young consumers.

\subsection{Differentials in Sophisticated Financial Products by Education}

In view of the income paths illustrated above, it should be apparent that college-educated consumers would optimally do relatively more saving (and borrowing), compared to the less-educated. In turn, this could make the better-educated group more interested than their less-educated peers in a technology that enhances returns on resources transferred across periods. Table 1 shows the fraction of PSID respondents which holds stocks, mutual funds, bonds, or individual retirement accounts (IRAs), arrayed by age and education. We denote these products as relatively "sophisticated," as compared to having only a simple bank account (or no saving at all).

[Table 1 here]

From these data, it is evident that college-educated households are much more likely to use a sophisticated technology for saving compared to high school dropouts. ${ }^{12}$ In particular,

\footnotetext{
${ }^{12}$ See Curcuru, Heaton, Lucas and Moore (2005) and Campbell (2006).
} 
more than $75 \%$ of older (age 55-65) college-educated respondents use sophisticated products compared to fewer than $32 \%$ of those with less than a high-school education (of the same age). The fact that people investing in more complex financial products earn higher returns relative to a bank account recalls Yitzhaki's (1987) evidence from tax returns and capital gains: he showed that households earning higher income also held more sophisticated assets, which in turn yielded higher returns. Calvet, Campbell, and Sodini (2007) examine Swedish data and conclude that expected portfolio returns differed across education groups. Bettereducated investor earned higher market returns fthan the less-educated.

The ability of the highly-educated and higher-paid to enjoy better returns may result from greater literacy about financial products. Some authors have suggested that limited numeracy and cognitive ability, or lack of financial sophistication, may explain investment or participation in the stock market (Christelis, Jappelli, and Padula, 2007; Kimball and Shumway, 2006; Van Rooij, Lusardi, and Alessie, 2011a). By contrast, in what follows we endogenize the motivation to take up sophisticated financial products as a way to motivate the emergence and persistence of wealth differences over the lifecycle.

\subsection{The Evolution of Financial Literacy by Education}

To evaluate household literacy about financial products, we use a rich new dataset: the 2009 US State-by-State National Financial Capability Survey (NFCS).${ }^{13}$ In particular, we use five questions from this Survey (reproduced in the Appendix) evaluating respondents' knowledge about interest compounding, risk diversification, inflation, the relationship between bond prices and interest rates and the relationship between mortage interest rates and payment horizons. These questions have been shown to been able to characterize financial knowledge and differentiate among levels of financial sophistication. ${ }^{14}$

We compute each person's fraction of correct answers to these five questions, with results displayed by age and education group in Table 2. Here we see that high-school dropouts perform much worse than the college-educated. The fact that literacy is initially higher

\footnotetext{
${ }^{13}$ For more information about the NFCS, see http://www.usfinancialcapability.org

${ }^{14}$ See Lusardi (2011) and Lusardi and Mitchell (2011).
} 
for the better-educated may indicate intergenerational transmission of financial literacy, or it may reveal some direct effect of education on literacy (for example, knowledge of mathematics and numeracy). ${ }^{15}$ Between the ages of 20 and 40, the median financial literacy score rises for all education groups, peaking in middle age; there is only a small decline thereafter to age $75 .{ }^{16}$

[Table 2 here]

In the next section we therefore build in endogenous acquisition of financial literacy in a way that traces patterns similar to those observed in the NFCS by age and education levels.

\section{The Model}

Our model of consumption over the life cycle allows uncertainty over asset returns, household income, and out-of-pocket medical expenditures. The consumer is assumed to choose his consumption stream by maximizing expected discounted utility, where utility flows are discounted by $\beta$. Decisions are made from time $t=0$ (assumed to be age 25) to age $T$ if the consumer is still alive $(T=100) .{ }^{17}$ The consumer also faces stochastic mortality risk. Adding to the heterogeneity created by the stochastic components, we also model the decisions of three different education groups (less than high school, high school, and college). Across these education groups, we allow for heterogeneity in income as well as out-of-pocket medical expenditure levels and capital market returns.

When making each per-period consumption decision yielding per-period benefit $u\left(c_{t}\right)$, the consumer may also elect to invest a portion of his resources in two different investment technologies. The first is a basic technology (for example, a checking account) which yields a certain (low) return $\bar{r}(\bar{R}=1+\bar{r})$. The second is more sophisticated and enables the

\footnotetext{
${ }^{15}$ This is consistent with Mandell (2008) who reports that high school students with higher literacy are those from college educated families. Lusardi, Mitchell, and Curto (2010) also show that financial literacy is higher among younger (age 23-28) respondents whose parents had stocks and retirement saving when they were teen-agers (12-17).

${ }^{16}$ Since the NFCS is a cross-sectional survey, we cannot control for cohort effects. Nonetheless our data are likely to generate flatter age profiles than cohort-specific ones. The increase at age 70 in the score for high-school dropouts is likely due to small sample size in the NFCS for that group (less than 100 observations per age-cell)

${ }^{17}$ From life tables, there is a $2 \%$ chance of living beyond that age so we cap the computations at that age.
} 
consumer to receive higher returns, but it comes at a cost. Specifically, the consumer must pay a direct cost (fee) to use the technology, $c_{d}$. The rate of return of the sophisticated technology is stochastic and the expectation of the return depends on the agent's level of financial literacy at the end of $t, \widetilde{R}\left(f_{t+1}\right)$. The stochastic return function is given by

$$
\widetilde{R}\left(f_{t+1}\right)=\bar{R}+r\left(f_{t+1}\right)+\sigma_{\varepsilon} \varepsilon_{t+1}
$$

where $\varepsilon_{t+1}$ is a $\mathrm{N}(0,1)$ iid shock and $\sigma_{\varepsilon}$ is the standard deviation of returns on the sophisticated technology. The function $r\left(f_{t+1}\right)$ is increasing in $f_{t+1}$ and represents the equity premium yielding higher returns on stocks. We denote by $d_{t+1}=1$ the use of the sophisticated technology and $d_{t}=0$ the use of the basic technology. ${ }^{18}$

Financial literacy evolves according to

$$
f_{t+1}=\delta(t) f_{t}+i_{t}
$$

where $\delta$ is a depreciation factor and $i_{t}$ is gross investment. Depreciation exists both because consumer financial literacy may decay, and also because some becomes obsolete as new financial products are developed. We let depreciation increase with age to reflect the general finding of cognitive decline at older ages (Agarwal, Driscoll, Gabaix, and Laibson, 2009). Gross investment has a price of $\pi_{i}\left(i_{t}\right)$, which includes both the monetary cost of advice and also the opportunity cost of time spent obtaining literacy. That cost is convex, reflecting decreasing returns in the production of literacy. ${ }^{19}$

Cash on hand is defined as

$$
x_{t}=a_{t}+y_{t}-o o p_{t}
$$

\footnotetext{
${ }^{18}$ Our model assumes a binary decision and a constant share of assets invested in the technology, rather than producing as an output the share of total assets invested in stocks. This simplication helps for computational reasons given we already are modeling an additional continuous decision, financial literacy investment. Data on the latter are also notoriously difficult to match as prior authors have noted (Cocco, Gomes, and Maenhout, 2005).

${ }^{19}$ One could allow for a direct disutility of investing in financial literacy and try to estimate it from the data. But because we are concerned mainly with the model's properties rather than its precise fit to the data, we abstract from the direct disutility channel.
} 
where $y_{t}$ is net household income and oopt represents out-of-pocket medical expenditure. Both of these variables are stochastic. End-of-period assets are given by

$$
a_{t+1}= \begin{cases}\widetilde{R}\left(f_{t+1}\right)\left(x_{t}-c_{t}-\pi\left(i_{t}\right)-c_{d}\right) & \text { if } d_{t+1}=1 \\ \bar{R}\left(x_{t}-c_{t}-\pi\left(i_{t}\right)\right) & \text { if } d_{t+1}=0\end{cases}
$$

We impose a borrowing constraint on the model such that assets $a_{t+1}$ have to be nonnegative. The consumer is guaranteed a minimum consumption floor of $c_{\min }$ (Hubbard, Skinner, and Zeldes, 1994). The sophisticated technology cannot be purchased if $x_{t}-c_{d}<$ $c_{\text {min }}$; that is the government does not pay for costs of obtaining financial advice (in this base case).

For an employed individual, the net household income process is given by a deterministic component which depends on education, age, and an $\operatorname{AR}(1)$ stochastic process

$$
\begin{aligned}
y_{t} & =g_{e}(t)+\mu_{t}+\nu_{t} \\
\mu_{t} & =\rho_{e} \mu_{t-1}+\varepsilon_{t} \\
\varepsilon_{t} & \sim N\left(0, \sigma_{\varepsilon}^{2}\right), v_{t} \sim N\left(0, \sigma_{v}^{2}\right)
\end{aligned}
$$

where $e$ represents an education group and $g_{e}(t)$ is an age polynomial (quadratic). Retirement is exogeneous at age 65. After retirement, we assume that the stochastic part of income is fixed at the value as of the retirement date. We estimate the age profile of household net income in retirement as a ratio of pre-retirement income from the data using an age polynomial (additional detail is provided below).

A similar stochastic $\mathrm{AR}(1)$ process is assumed for out-of-pocket medical expenditures. Because these expenditures are generally low prior to retirement (and to save on computation time), we allow only for risk in medical expenditures after retirement (as in Hubbard, Skinner, and Zeldes, 1994). Finally, we allow for mortality risk at all ages, drawing on the 2004 life-table and denoting $p_{t}$ as the one-year survival probability. 
If we denote the non-deterministic components of income and out-of-pocket expenditures as $\eta_{y}$ and $\eta_{o}$, respectively, then the state-space in period $t$ is defined as $s_{t}=$ $\left(\eta_{y, t}, \eta_{o, t}, e, f_{t}, a_{t}\right)$. The decisions are given by $\left(c_{t}, i_{t}, d_{t+1}\right)$. We represent the problem as a series of Bellman equations such that, at each age and for each technology choice, the value function has the form

$$
\begin{aligned}
& V_{d}\left(s_{t}\right)=\max _{c_{t}, i_{t}} u\left(c_{t}\right)+\beta p_{t} \int_{\varepsilon} \int_{\eta_{y}} \int_{\eta_{o}} V\left(s_{t+1}\right) d F\left(\eta_{o}\right) d F\left(\eta_{y}\right) d F(\varepsilon) \\
& a_{t+1}= \begin{cases}\widetilde{R}\left(f_{t+1}\right)\left(x_{t}-c_{t}-\pi\left(i_{t}\right)-c_{d}\right) & \text { if } d_{t+1}=1 \\
\bar{R}\left(x_{t}-c_{t}-\pi\left(i_{t}\right)\right) & \text { if } d_{t+1}=0\end{cases} \\
& f_{t+1}=\delta(t) f_{t}+i_{t}
\end{aligned}
$$

If technology can be accessed, the value function is given by $V\left(s_{t}\right)=\max \left(V_{0}\left(s_{t}\right), V_{1}\left(s_{t}\right)\right)$.

The model is solved by backward recursion after discretizing the continuous statevariables. At each point in the state-space, we use a grid search to search for the optimal solution of consumption and financial literacy investment. After we find an initial solution on a coarse grid, we refine the grid around that point and repeat. At each point in the state-space, we do this procedure for both technology choices before choosing which one is optimal. We use 35 net asset points and 20 financial literacy points to create the statespace, and we use linear intrapolation to find the value function when net assets or financial literacy stock at $t+1$ falls off the grid. The value function behaves smoothly and relatively linearly except at low levels of net assets, where liquidity constraints and the consumption floor bind. Hence, the grid for assets in the state-space is defined as equally-spaced points on $a^{0.5}$, which leads to more points at lower levels of net assets. We use the method proposed by Tauchen (1986) to discretize the processes for income and out-of-pocket median expenditures (with 8 points each). In total, optimal decisions are computed more than six million times. 


\section{Calibration}

To implement the model, we assume that $u\left(c_{t}\right)$ has a CRRA form with relative risk aversion $\sigma$. To take account of household size, we follow Scholz, Seshadri, and Khitatrakun (2006) and define an equivalence scale which takes account of differences in household size by education group and changes in demographics over the lifecycle to affect consumption (following Attanasio, Banks, Meghir, and Weber, 1999). Let $z(j, k)=(j+0.7 k)^{0.75}$ where $j$ is the number of adults in household and $k$ is the number of children (less than 18 years old). We then define $n_{e, t}=z\left(j_{e, t}, k_{e, t}\right) / z(2,1)$ where $j_{e, t}$ and $k_{e, t}$ are the average number of adults and children in the household by age and education group. Equivalized household utility is then defined as

$$
v_{e, t}\left(c_{t}\right)=n_{e, t} u\left(\frac{c_{t}}{n_{e, t}}\right)
$$

We use PSID data to estimate the time-series of average equivalence scales by education group. ${ }^{20}$ We use a discount factor of 0.97 and a value of $\sigma=2.6$. These are fairly standard values used in the consumption literature: Hubbard, Skinner, and Zeldes (1994) use a discount factor of 0.97 and relative risk aversion of 3, and French (2005) estimates risk aversion varying from 2.1 to 2.7 and a discount factor ranging from 0.98 to 0.99 .

The minimum consumption floor is set at $\$ 10,000$ per couple with one child.${ }^{21}$ Computing post-retirement income as a function of pre-retirement income is notoriously difficult because retirement is in part endogeneous. Here we compute average net household income of retirees and non-retirees by education and age group. Next, we compute the ratio of the average retired household's net income at age $65+$ as a function of the average working household's net income as of age 64 . This yields a retirement replacement rate at age 65 of around $75 \%$

\footnotetext{
${ }^{20}$ We compute the average number per household of adults and children (under 18 years old) by the head's education and age. We then compute the equivalence scale according to the formula above.

${ }^{21}$ We arrive at this value using data from the Office of the Assistant Secretary for Planning and Evalution (ASPE, 2008), where the maximum benefit payable to a couple with one child under TANF was $\$ 495$ (\$06). The average monthly benefit of recipients on food stamps (for a 3-person household) was $\$ 283$. Hence, prior to age 65 , the sum of TANF and food stamp benefits equalled $\$ 778$ for a 3 -person household or $\$ 9,336$ annually (omitting the lifetime limit on TANF receipt). Data from the Social Security Administration (http://www.ssa.gov/pressoffice/factsheets/colafacts2004.htm) shows that the maximum federal monthly payment for SSI for a single household was $\$ 552$ and $\$ 829$ to a couple; adding food stamps to this amount yields a value of $\$ 7620$ to singles and $\$ 12,180$ for couples.
} 
for high-school dropouts and high-school graduates, and of $64 \%$ for college graduates. These are higher than replacement rates purely based on Social Security because households have other sources of retirement income (spousal income, employer pension income, annuities, etc). They are close to total retirement income estimates published elsewhere (c.f. Aon Consulting, 2008).

The return on the safe asset is set to $\bar{r}=1 \%$ (net of inflation). We use an equity premium of $4 \%^{22}$ for the rate on the sophisticated technology if someone has acquired maximum financial literacy. We use data from the PSID to compute the share of wealth invested in equity and IRAs, yielding a figure of $25 \%$ for high-school dropouts, $30 \%$ for high school graduates, and $34 \%$ for college graduates. Since we do not model the intensive margin or how much wealth is invested in the sophisticated technology, we use a value of $30 \%$ in what follows (the average share among all those participating in stocks and IRAs). The maximum premium when using the sophisticated technology is thus set to 0.015 . With the power of compound interest that additional return can imply up to $80 \%$ increase in wealth after 40 years (roughly the horizon for retirement if the consumer is initially 25 years old). To facilitate interpretation, we set the maximum of financial literacy to 100 and its minimum to 0 . Hence, we let $R\left(f_{t+1}\right)=0.015 \times f_{t} / 100 .{ }^{23}$ The standard deviation of the equity premium is set to a value of 0.15 , consistent with Cocco, Gomes, and Maenhout (2005). Hence, since 0.30 of wealth may be invested in the sophisticated technology, the standard deviation of the return for that technology is set to 0.06 .

We estimate both income and out-of-pocket processes using the minimum distance method from Hubbard, Skinner, and Zeldes (1994). We first estimate by OLS the deterministic part of household income profiles using PSID data from 1980-99 and we then use the residuals to estimate the $\mathrm{AR}(1)$ processes. The out-of-pocket medical expense process is estimated using the same methodology. ${ }^{24}$ Following the literature (Hubbard, Skinner and

\footnotetext{
${ }^{22}$ See Cocco, Gomes, and Maenhout (2005).

${ }^{23} \mathrm{We}$ chose a linear function for ease of interpretation. In part, this implies that financial literacy can be rescaled to be interpreted in terms of returns which in principle could be observable and used to calibrate the model. Data from Calvet, Campbell, and Sodini (2007) can be used to compute expected returns as a function of education and age. Similar data from the U.S. are not available.

${ }^{24}$ Estimates of covariance parameters are reported in Appendix 2.
} 
Zeldes, 1994; Scholz, Seshadri, and Khitatrakun, 2006) we set the variance of the transitory error component to zero in the simulations as it likely reflects measurement error.

Estimating the price of acquiring financial literacy from available data is difficult. If we adopt a production function with decreasing returns, the cost of producing one unit depends on the price of the inputs but also on total factor productivity which is unidentified unless we can measure both inputs and outputs. We also seek to take into account the difficulty of learning about financial products, which might be a result of low productivity of time and money in producing financial literacy. In fact, financial services can be quite expensive. For example, the cost of a one-hour consultation may cost up to $\$ 250 .{ }^{25}$ The productivity of time and money could vary with education (which we will examine in future research). For now, we avoid building other differences across education groups which would create different investment and saving profiles. We use the simulated and actual distribution of financial literacy from the NFCS to fit these parameters. We use the following cost formula

$$
\pi\left(i_{t}\right)=75 i_{t}^{1.75}
$$

which leads to a convex cost schedule. The first unit of investment is assumed to cost $\$ 75$.

Depreciation in financial literacy is also difficult to calibrate from available sources. We use the lifecycle path of financial literacy estimated from the NFCS to calibrate these parameters. To reflect the fact that cognitive skills and memory are likely better at younger ages than at older ones (Agarwal, Driscoll, Gabaix, and Laibson, 2009), we assume a rate of depreciation of $2.5 \%$ from age 25 to age 50 and let it decrease at a rate of $0.1 \%$ per year after that age.

The cost of using the sophisticated technology is fixed at $\$ 1000$. To provide a sense of the magnitudes involved here, Vissing-Jorgensen (2002) estimates the distribution of fixed

\footnotetext{
${ }^{25}$ See Turner and Muir (2011). As another example Veritat.com offers financial planning at $\$ 25$ a month for singles and $\$ 40$ for families ( $\$ 35$ for retirees) plus an initial planning fee of $\$ 250$. Accordingly the first-year cost is $\$ 550$ for singles and $\$ 730$ for families. Less-expensive alternatives include financial advice software; for instance the cost of a one-year license to use ESPlanner is $\$ 40$ while the cost of ESPlanner extensive is $\$ 149$ (www.esplanner.com/product_catalog).
} 
costs for stock market participation in the PSID using a static portfolio model. Her median estimate is $\$ 750$ (in 2004 dollars). Of course, these estimates are derived from a simple twoperiod stock market participation model, while the model used here is richer. We choose the value of $\$ 1000$ to roughly match the fraction of sophisticated consumers at age 65 .

\subsection{Simulation}

Upon finding the consumer's optimal consumption, financial literacy investment, and technology choices at each point in the state-space and at each age, we use our decision rules to simulate 2,500 individuals moving through their lifecycles. These consumers are given the initial conditions for education, earnings, and assets that we have derived from the PSID for persons age 25 to 30 . We initialize financial literacy assuming a normal distribution with a mean that depends on education level estimated from the NFCS; the index we use is the fraction of correct answers (out of five financial literacy questions). We then draw income shocks, out-of-pocket medical expenditure surprises, and rate of return shocks, and we simulate the lifecycle paths of all consumers. Linear intrapolation is used when simulated state-variables fall between gridpoints.

\subsection{General Fit of the Basic Model}

Figure 3 shows how moments from the simulated results compare to moments from the data presented in Section 2. In the first panel, we see that our model captures differences in asset accumulation by education group quite well. In particular, the model predicts the large observed dispersion: at age 65 , for instance, median net assets are $\$ 153,855$ in the lowest education group, while they are $\$ 395,864$ for the college-educated. Thus the simulated median college graduate has 2.6 times the net assets of a dropout, close to the observed ratio of 2.7 in the data. Unlike Cagetti (2003), our model can do this without resorting to differences in preferences (e.g. risk aversion and patience). The main mechanism in our

model is that there are differences in take-up patterns of the sophisticated technology and hence differences in returns. In turn, these return and take-up differences are amplified 
by differences in the accumulation of financial literacy. The simulated asset paths over the lifecycle by education group are of interest, even if they do not exactly match what is observed in the PSID. They do match around the time of retirement, though asset holdings are somewhat low early in the lifecycle.

[Figure 3 here]

In the second panel of Figure 3, we show that initial differences in financial literacy are maintained over the lifecycle. Despite depreciation in financial literacy, the model predicts that consumers invest in financial literacy - not only to maintain but to increase their financial literacy. As observed in the data, financial literacy peaks around the time of retirement and declines slowly afterward. This is because investment in financial literacy is not constant over the lifecycle: it tends to be positive early on and declines with age. Eventually the force of depreciation, which rises with age due to cognitive decline, offsets gross investment producing a tapering off of financial literacy in later years. Financial literacy at age 65 is very well-matched, as can be seen from Table 3. Dropouts have an average financial literacy score of 44.1 in the simulation ,compared to 46.9 in the data. College graduates' average financial literacy score is 80.6 in our model, compared to 80.1 in the data.

[Table 3 here]

Drawing on the simulations, we compute the fraction of consumers that optimally and endogenously acquires very little financial literacy. Table 3 shows the simulated proportion of consumers with low literacy (scoring less than 25 out of 100) and the results confirm that our model does a decent job tracking differences by educational levels. For example, the model predicts that at age $65,50.1 \%$ of dropouts have low literacy as compared to $7.6 \%$ for college graduates. We also predict an increase in low literacy with age while the data show a decrease. The last panel of Figure 3 reveals that the model does a good job in predicting the large differences in the use of the sophisticated technology, although age profiles do not match exactly. For example, we predict that at age $65,39.6 \%$ of dropouts participate in the sophisticated technology, compared to $80.4 \%$ among college graduates. Those figures 
are respectively $21.4 \%$ and $73.7 \%$ in the data. We underpredict participation at younger ages and over-predict at older ages; to fit participation at younger ages, we would need a lower cost for using the technology. But then differences across education groups would not be as well-replicated as they are now. Hence, if our objective were to provide the best fit of the data, we could allow the cost of using the technology to depend negatively on financial literacy. Instead, our goal is to understand the forces at play in a lifecycle model that features financial literacy. Hence we avoid building in additional differences across education groups that would make the mechanisms less transparent.

\section{$5 \quad$ Policy Simulations}

In this section, we investigate a number of scenarios that may alter literacy investment, technology participation, and net assets. First, we examine what would happen if all consumers were completely financially literate. This allows us to posit a benchmark where there is no welfare loss when a consumer acquires financial literacy. In other words, this mimics the possibility that consumer investment in the sophisticated technology might be provided by a free financial advisor who could offer exposure to the full equity premium.

Because government policy can affect consumers' income profiles as well as their insurance against risk, we also consider three different policy simulations. Our next experiment reduces retirement benefits for all groups by $25 \%$ : since we predict that reducing the benefit replacement rate should boost the need to save, we are interested in the implications for financial literacy investment. The subsequent experiment halves the consumption floor from $\$ 10,000$ to $\$ 5,000$, thereby reducing protection the most for the least-educated consumers. A final experiment increases income uncertainty, by increasing the standard deviation of the permanent income shock by $25 \%$. 


\subsection{Full Literacy}

To contrast a scenario where knowledge is imperfect and costly with one where there is complete knowledge, we next assume that consumers start off with a financial literacy stock of 100 and there is no depreciation. Since negative investment in financial literacy is ruled out, this implies full literacy across the entire lifecycle. As a result of this change, a consumer using the sophisticated technology earns the full equity premium. In Figure 4, we show the results of such a simulation. We plot the simulated paths in this scenario (solid lines) and the baseline scenario with imperfect literacy (dotted lines).

[Figure 4 here]

Compared to our previous results, it is not surprising that financial literacy for the most-educated consumers changes little in this scenario. By contrast, important changes are observed for both the dropouts and the high school graduates. As described in Table 4, with full literacy, both groups save more and invest more in the sophisticated technology. Median net retirement assets increase by $\$ 17,878$ (4.5\%) for the college-educated while they rise by $\$ 27,505(18 \%)$ among dropouts. The fraction of dropouts using the sophisticated technology at the time of retirement goes up by more than 32.3 percentage points (from $39.6 \%$ to $71.9 \%$ ). The large positive effects for the least-educated illustrate the tremendous costs of imperfect financial literacy: knowledge allows individuals to invest in high return assets and results in much higher wealth accumulation at the time of retirement.

[Table 4 here]

Wealth differences by education group also shrink substantially. In the baseline, the ratio of median net assets between college graduates and dropouts was 2.6, while it shrinks to 2.28 with perfect knowledge, a $12 \%$ drop. Hence this simulation suggests that financial illiteracy contributes to wealth inequality. Moreover, the results suggest that making financial literacy less costly could have a relatively powerful impact on the wealth accumulation of the lesseducated. 


\subsection{Lowering the Retirement Benefit Replacement Rate}

As discussed in Section 4, the average retirement income replacement rate estimated in the data is $75 \%$ for both dropouts and high school graduates, and $65 \%$ for college graduates. In this next experiment, we examine the effect of reducing replacement rates by 25 percentage points for all three groups, from the time of retirement until death. This experiment mimics a change in policy where, for example, benefits are cut for all retirees. The retirement system becomes less generous and individuals have to provide more for their own retirement security.

Figure 5 shows the effects on assets and financial literacy. Because of the crowdout effect that retirement benefits have on saving, we would expect assets to increase when the replacement rate declines. A simple lifecycle model would predict perfect offset. But since our model features liquidity constraints and uncertainty in income, the crowd-out effect may be much less than complete. The results indicate that median net assets at the time of retirement rise by $13 \%$ among dropouts, $17.6 \%$ among high school graduates, and $11 \%$ among college graduates (see Table 4).

[Figure 5 here]

Since the need to save has increased, financial literacy also rises. Average financial literacy increases by $6 \%$ for dropouts, $9 \%$ for high-school graduates and $4.7 \%$ for college graduates. Accordingly, as described in Table 4, the share of those with little knowledge declines across all education groups, i.e., it is not optimal to have low knowledge when individuals are in charge of their own retirement saving. Thus, retirement benefits not only crowd out private saving, but also financial literacy.

\subsection{Lower Means-Tested Government Transfers}

Several authors note that goverment transfers provide private saving disincentives by promising an effective minimum consumption floor (c.f. Hubbard, Skinner and Zeldes, 1994). This is particularly true for dropouts, who face the highest probability of being at the consumption floor. For this reason, our next simulation reduces that consumption floor from $\$ 10,000$ 
to $\$ 5000$ and results appear in Figure 6. As expected, saving by the least-educated respond most to a reduction in consumption insurance. For dropouts, net median assets as of retirement jump by $21 \%$ (to $\$ 186,932$ from $\$ 153,855$ ). For high-school graduates the rise in net assets is $10 \%$ while for college graduates, the increase is still substantial, at $6.7 \%$.

[Figure 6 here]

Investment in financial literacy also increases in this scenario, particularly after age 45 when labor income drops and the likelihood of hitting the consumption floor increases. Average financial knowledge at the time of retirement increases the most among high school drop-outs, where financial literacy rises by about 10 percentage points. By contrast, financial literacy of college-educated individuals increases by 4 percentage points. Evidently financial literacy investment is akin to an insurance mechanism, used to boost saving via higher rates of return. As a result of the increase in financial literacy, the fraction using the sophisticated technology increases by 6 percentage points for dropouts.

\subsection{Increasing Income Uncertainty}

Because income uncertainty along with a liquidity constraint lead to precautionary saving, our last simulation assesses how responsive financial literacy investment is to income uncertainty. In particular, we increase the standard deviation of the permanent and transitory income shock by 25\%; results are shown in Figure 7 . Because income is riskier in this scenario, consumers of all education levels save more, particularly those least likely to benefit from social insurance (i.e., those least likely to hit the consumption floor). The need to save rises substantially, so as to self-insure against income shocks which are now more volatile. By contrast with the previous scenario, the mostly highly-educated increase their saving the most: median net assets increase by $8 \%$ (and only by $4 \%$ for dropouts.) As in other models of precautionary saving, an increase in uncertainty does not generate high amounts of wealth, particularly for those who are covered by social insurance (see Hubbard, Skinner and Zeldes, 1994). The better-educated also invest more in financial literacy, in particular during the second-half of the lifecycle. Although these changes are somewhat more modest 
than those found in the prior case, we can safely conclude that financial literacy can provide important protection against income shocks.

[Figure 7 here]

\section{Discussion and Conclusions}

This paper offers an augmented stochastic lifecycle model that endogenizes the decision to acquire financial literacy. Our approach acknowledges that financial literacy does offer higher expected returns, but it is costly to acquire and depreciates with time. The optimal financial literacy profile is shown to be hump-shaped over the lifecycle, and it also differs by education group because of differences in lifecycle income paths. We also demonstrate that allowing for endogeneous financial literacy creates large differences in wealth holdings and that social insurance influences the incentives to acquire financial literacy.

We provide three contributions to existing models of saving and household wealth accumulation. First, the model generates wealth inequality above and beyond what traditional models of saving normally deliver. Accordingly we can rationalize some of the large differences in wealth found in most empirical works on saving, by relying on an important fact: individuals do not start their economic lives with full financial knowledge and that knowledge is acquired endogenously over the lifecycle. Second, some levels of financial ignorance may actually be optimal. As demonstrated in many empirical papers, many individuals display very little financial literacy. Our paper explains why some may rationally fail to invest, since it is expensive to acquire financial knowledge and not everybody benefits from greater financial sophistication. Third, financial literacy can be an important public policy lever. For example, a policy initiative that reduced the cost of financial literacy - such as providing financial education in school or setting up websites that made it easier to acquire information - would have large effects on both wealth accumulation and wealth inequality. According to our estimates, a substantial share of wealth can be attributed to being able to utilize a sophisticated technology that allows individuals to invest in higher-return as- 
sets. Similarly, policy initiatives such as personal accounts under social insurance schemes and increased reliance on individually-managed retirement accounts will be accompanied by more financial knowledge as well as wealth inequality. Moreover, a rise in income risk, such as that which characterizes the current macroeconomy, will be accompanied by an increase not only in precautionary saving but also an increase in financial literacy.

While our paper is not the first to propose that financial literacy is a choice variable and endogenously determined, it is the first to add financial literacy to an intertemporal stochastic model of saving. Thus Jappelli and Padula (2011) discuss investments in financial literacy but they use a simple two-period model and do not track how differences in literacy levels induce differential wealth outcomes. Delavande, Rohwedder, and Willis (2008) also posit that investment in financial knowledge is akin to human capital investment, but their static model cannot trace lifecycle wealth patterns. By contrast, our ability to dynamically model investments in financial literacy in a rich intertemporal setting with decision-making under many sources of uncertainty allows us to evaluate the quantitative importance of financial literacy and to perform several important policy experiments. Moreover, our work can explain many of the findings reported in other papers. For example, our model is consistent with results in Behrman et al. (2010), Lusardi and Mitchell (2011), and Van Rooij, Lusardi, and Alessie (2011b), who document a positive empirical link between financial literacy and wealth holdings even after controlling for endogeneity of financial literacy. Additionally our analysis is consistent with Kimball and Shumway (2006), Christelis, Jappelli, and Padula (2010), Yoong (2011) and others who show that persons with higher levels of financial literacy are also more likely to participate in the stock market, which in our model is represented by the use of the sophisticated technology.

Finally, our model can rationalize and account for at least some of the observed differences in wealth holdings across education groups. While other authors have had to rely on social insurance and preference parameters to produce similar dispersion, our model shows that endogenizing financial literacy can go a long way toward explaining wealth differences over the lifecycle and across education groups. In a world where individuals are increasingly 
asked to take on responsibility to save and provide for their own retirements, and where consumers are confronted with complex financial markets, it is important to start incorporating financial knowledge into our models of saving. People display different levels of financial knowledge early in life, and this simple feature has important implications for how much people save. By incorporating more realistic features in our theoretical models, we will be better equipped to match the data, make predictions for the future, and generate better recommendations for public policy.

\section{References}

[1] Agarwal, S., J. Driscoll, X. Gabaix, and D. Laibson (2009): "The Age of Reason: Financial Decisions over the Life-Cycle and Implications for Regulation." Brookings Papers on Economic Activity, Issue 2: 51-117.

[2] Assistant Secretary for Planning and Evalution (ASPE, 2008) (see http://aspe.hhs.gov/hsp/indicators08/apa.shtml\#ftanf2).

[3] Angeletos, G.M., D. Laibson, A. Repetto, J. Tobacman and S. Weinberg (2001). "The Hyperbolic Consumption Model: Calibration, Simulation and Empirical Evaluation." Journal of Economic Perspectives, 15(3): 47-68.

[4] Aon Consulting (2008). Replacement Ratio Study: A Measurement Tool for Retirement Planning. Global Corporate Marketing and Communications (www.aon.com/retire).

[5] ASPE. (2008) Indicators of Welfare Dependence Appendix A. http://aspe.hhs.gov/hsp/indicators08/apa.shtml\#ftanf2.

[6] Attanasio, O., J. Banks, C. Meghir and G. Weber. (1999): "Humps and Bumps in Lifetime Consumption." Journal of Economic and Business Statistics, 17(1), 23-35. 
[7] Behrman, J., O.S. Mitchell, C. Soo, and D. Bravo (2010): "Financial Literacy, Schooling, and Wealth Accumulation." NBER WP 16452.

[8] Bernheim, B.D., J. Skinner, and S. Weinberg. (2001): "What Accounts for the Variation in Retirement Wealth among U.S. Households?" American Economic Review, 91 (September): 832-57.

[9] Cagetti, M. (2003): "Wealth Accumulation Over the Life Cycle and Precautionary Savings." Journal of Business and Economic Statistics, 21:3, 339-353.

[10] Calvet, L., J.Y. Campbell and P. Sodini (2007): "Down or Out: Assessing the Welfare Costs of Household Investment Mistakes." Journal of Political Economy, 115(5): 707-747.

[11] Campbell, J.Y. (2006). "Household Finance." Journal of Finance, 61: 1553-1604.

[12] Campbell, J.Y. and N. G. Mankiw (1989). "Consumption, Income and Interest Rates: Reinterpreting the Time Series Evidence." In NBER Macroeconomics Annual, Eds. O.J. Blanchard and S. Fischer. Cambridge: MIT Press: 185-216.

[13] Campbell, J.Y. and L. Viceira (2002). Strategic Asset Allocation. Oxford: Oxford University Press.

[14] Cocco, J., F. Gomes, and P. Maenhout (2005). "Consumption and Portfolio Choice over the Life-Cycle." Review of Financial Studies, 18: 491-533.

[15] Curcuru, S., J. Heaton, D. Lucas, and D. Moore (2005), "Heterogeneity and Portfolio Choice: Theory and Evidence." In Handbook of Financial Econometrics, Y. Ait-Sahalia and L.P. Hansen, (eds), Elsevier Science, Amsterdam.

[16] Christelis, D., T. Jappelli and M. Padula (2010). "Cognitive Abilities and Portfolio Choice." European Economic Review, 54: 18-38. 
[17] Delavande, A, S. Rohwedder, and R.J. Willis (2008). "Preparation for Retirement, Financial Literacy and Cognitive Resources." MRRC Working Paper Series 190 .

[18] French, E. (2005). "The Effects of Health, Wealth, and Wages on Labour Supply and Retirement Behaviour." The Review of Economic Studies, 72(2): 395-427.

[19] Gourinchas P.-O., and J.A. Parker (2002). "Consumption Over the Life Cycle." Econometrica, January vol. 70(1): 47-89

[20] Huang, K., and F. Caliendo (2009). "Rationalizing Seven Consumption-Saving Puzzles in a Unified Framework." Utah State University Working Paper.

[21] Hubbard, R.G., J. Skinner, and S. Zeldes (1994). "Precautionary Savings and Social Insurance." Journal of Political Economy, 103(2): 360-399.

[22] Hurst, E., A. Kennickell, A. Lusardi, and F. Torralba (2010). "Precautionary Savings and the Importance of Business Owners." Review of Economics and Statistics, 92(1): 61-69.

[23] Jappelli, T., and M. Padula (2011). "Investment in Financial Literacy and Saving Decisions." CSEF Working Paper 272, University of Salerno.

[24] Juster, F.T., J.P. Smith and F. Stafford (1999). "The Measurement and Structure of Household Wealth." Labour Economics. 6(2): 253-275.

[25] Kimball, M. and T. Shumway (2006). "Investor Sophistication and the Home Bias, Diversification, and Employer Stock Puzzles." University of Michigan Working Paper.

[26] Kimball, M. (1990). "Precautionary Saving in the Small and in the Large." Econometrica, vol. 58(1), January: 53-73.

[27] Lusardi, A., and O.S. Mitchell (2011). "Financial Literacy and Planning: Implications for Retirement Wellbeing." In Financial Literacy: Implications for 
Retirement Security and the Financial Marketplace. Eds O.S. Mitchell and A Lusardi. Oxford: Oxford University Press (forthcoming).

[28] Lusardi, A., and O.S. Mitchell (2007a). "Baby Boomer Retirement Security: The Roles of Planning, Financial Literacy, and Housing Wealth." Journal of Monetary Economics, 54: 207-224.

[29] Lusardi, A. and O.S. Mitchell. (2007b). "Financial literacy and Retirement Preparedness. Evidence and Implications for Financial Education." Business Economics, January: 35-44.

[30] Lusardi, A. and O.S. Mitchell (2009). "How Ordinary Consumers Make Complex Economic Decisions: Financial Literacy and Retirement Readiness." NBER Working Paper 15350.

[31] Lusardi, A., O.S. Mitchell, and V. Curto (2010). "Financial Literacy and Financial Sophistication among Older Americans." Journal of Consumer Affairs, 44(2): $358-380$.

[32] Lusardi, A. (2011). "Americans' Financial Capability." NBER Working Paper 17103.

[33] Mandell, L. 2008. "Financial Education in High School." In: Annamaria Lusardi (ed.), Overcoming the Saving Slump: How to Increase the Effectiveness of Financial Education and Saving Programs, Chicago: University of Chicago Press, $257-279$.

[34] Moore, J., and O.S. Mitchell (2000). "Projected Retirement Wealth and Saving Adequacy". In Forecasting Retirement Needs and Retirement Wealth. Eds. O.S. Mitchell, B. Hammond, and A. Rappaport. Philadelphia, PA: Univ. of Pennsylvania Press: 68-94. 
[35] Poterba, J., S. Venti, and D. Wise (2009). "The Decline of Defined Benefit Retirement Plans and Asset Flows." In Social Security Policy in a Changing Environment. Eds J. Brown, J. Liebman, and D. Wise. Chicago: University of Chicago Press: 333-379.

[36] Scholz, J., A. Seshadri, and S. Khitatrakun (2006). "Are Americans Saving Optimally for Retirement?" Journal of Political Economy, 114(4): 607-643.

[37] Tauchen, G. (1986): "Finite State Markov-Chain Approximations to Univariate and Vector Autoregressions." Economic Letters, 20: 177-181.

[38] Turner, J. A., and D. Muir (2011). "The Market for Financial Advisers." Pension Policy Center Working Paper. Washington, D.C.

[39] Van Rooij, M., A. Lusardi,ăand R. Alessie. 2011a. Financial literacy and stock market participation, Journal of Financial Economics101 (2): 449-472.

[40] Van Rooij, M., A. Lusardi,ăand R. Alessie. 2011b. Financial literacy, retirement planning and household wealth. NBER Working Paper 17339.

[41] Venti, S., and D. Wise (2000). "Choice, Chance and Wealth Dispersion at Retirement." InAging Issues in the United States and Japan. Eds. S. Ogura, T. Tachibanaki, and D.A. Wise. Chicago: Univ. of Chicago Press: Chicago, IL: 25-64.

[42] Vissing-Jorgensen, A. (2002). "Towards an Explanation of Household Portfolio Choice Heterogeneity: Nonfinancial Income and Participation Cost Structures." NBER Working Paper 2884, 2002.

[43] Yitzhaki, Shlomo (1987). "The Relation between Return and Income." Quarterly Journal of Economics, 102 February: 77-95. 


\section{Appendix 1: List of Financial Literacy Questions from the National Financial Capability State-by-State Survey (NFCS)}

- Suppose you had $\$ 100$ in a savings account and the interest rate was $2 \%$ per year. [After 5 years, how much do you think you would have in the account if you left the money to grow? [1 More than $\$ 102 ; 2$ Exactly $\$ 102 ; 3$ Less than $\$ 102 ; 98$ Don’t know; 99 Prefer not to say.]

- Imagine that the interest rate on your savings account was $1 \%$ per year and inflation was $2 \%$ per year. After 1 year, how much would you be able to buy with the money in this account? [1 More than today; 2 Exactly the same; 3 Less than today; 98 Don't know; 99 Prefer not to say]

- If interest rates rise, what will typically happen to bond prices? [1 They will rise; 2 They will fall; 3 They will stay the same; 4 There is no relationship between bond prices and the interest rate; 98 Don't know; 99 Prefer not to say]

- A 15-year mortgage typically requires higher monthly payments than a 30-year mortgage, but the total interest paid over the life of the loan will be less. [1 True; 2 False; 98 Don't know; 99 Prefer not to say]

- Buying a single company's stock usually provides a safer return than a stock mutual fund. [1 True; 2 False; 98 Don't know ; 99 Prefer not to say] 
Appendix 2: Estimates of Income and Out-of-Pocket Medical Expenditure Process

\begin{tabular}{|c|c|c|c|}
\hline Covariance Structure & $<$ HS & HS & College + \\
\hline \hline \multicolumn{4}{|c|}{ Log Income Process } \\
\hline$\rho$ & 0.936 & 0.933 & 0.928 \\
\hline$\sigma_{\varepsilon}^{2}$ & 0.052 & 0.034 & 0.032 \\
\hline$\sigma_{v}^{2}$ & 0.117 & 0.176 & 0.078 \\
\hline \multicolumn{4}{|c|}{ Log Out-of-Pocket Process } \\
\hline$\rho$ & 0.802 & 0.762 & 0.794 \\
\hline$\sigma_{\varepsilon}^{2}$ & 0.246 & 0.303 & 0.257 \\
\hline$\sigma_{v}^{2}$ & 0.758 & 0.581 & 0.604 \\
\hline
\end{tabular}

Table A1: Covariance Structure for Log Income and Out-of-Pocket Medical Expenditures 


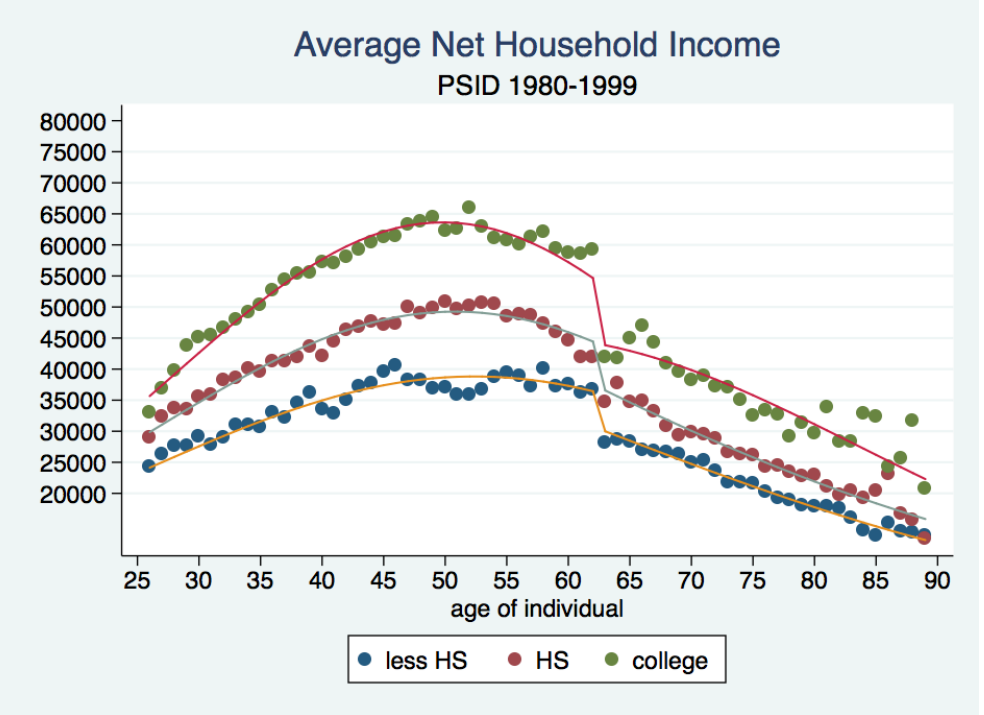

Figure 1: Lifecycle Net Household Income Profiles by Educational Attainment. This Figure shows average net household income computed from the PSID waves 1980-1999 (see text). The profile uses workers up to age 65 and retirees age $65+$ to show how income drops at age 65. The Figure adjusts for cohort effects based on regressions with age controls. 


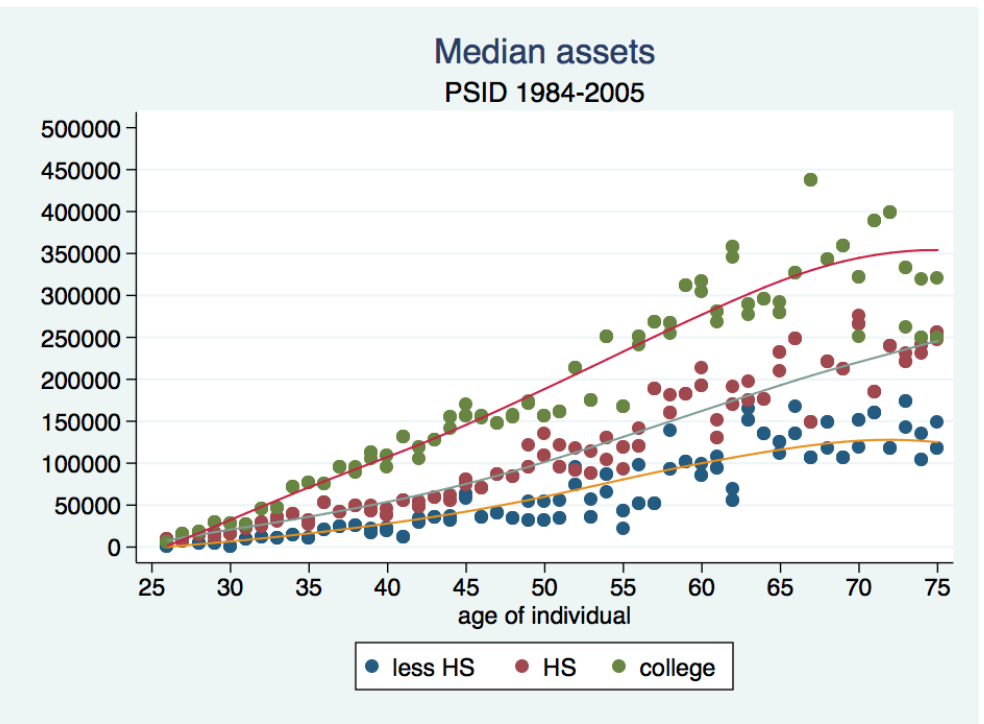

Figure 2: Median Lifecycle Net Assets by Educational Attainment. This Figure shows median asset profiles by education group derived using the PSID (see text). The lines are predicted from median regressions where a correction is made for cohort effects (following French (2005)); assets include the sum of assets minus all debt. 


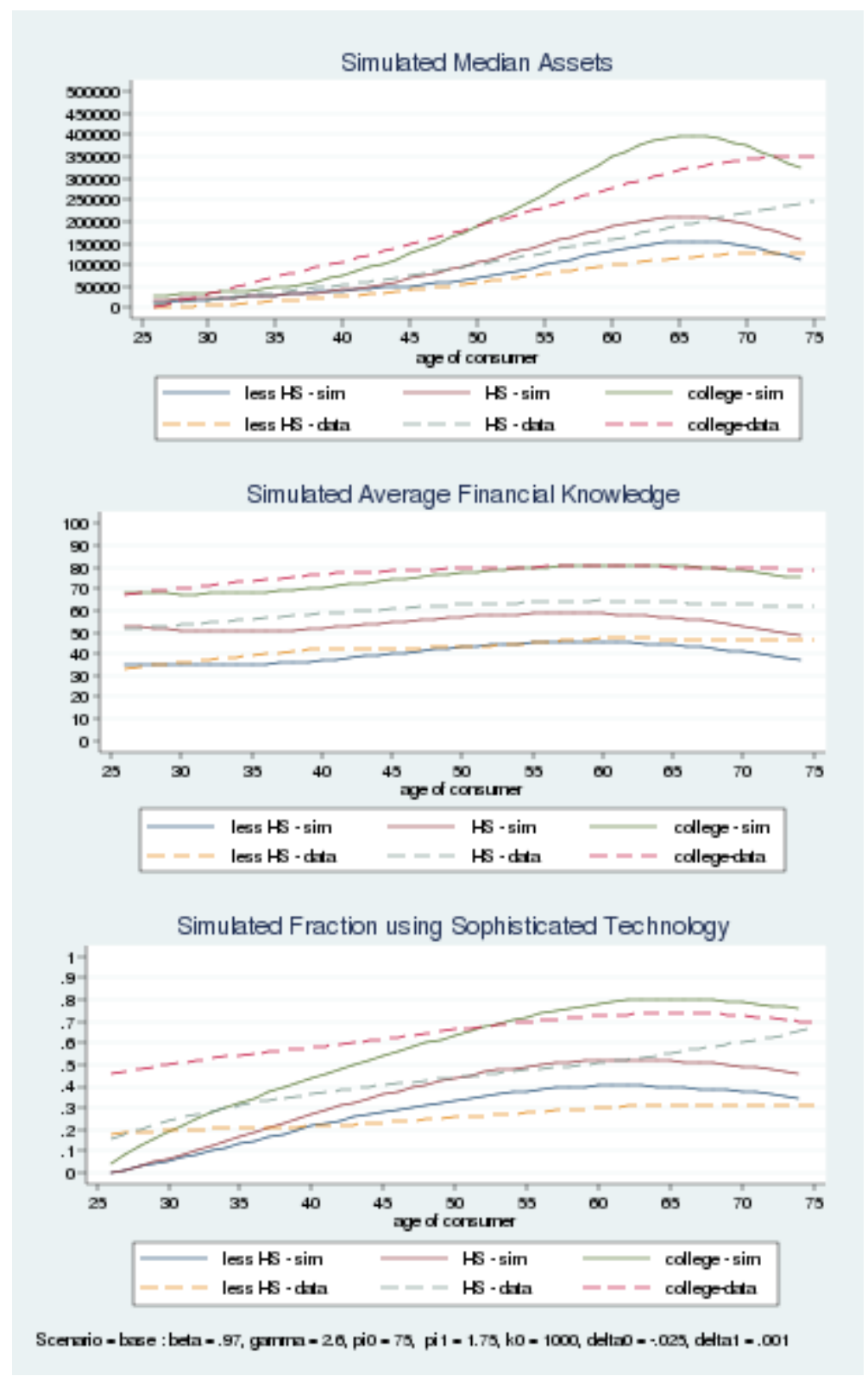

Figure 3: Net Assets, Financial Knowledge, and Percent Using Sophisticated Technology by Educational Attainment: Comparison of Lifecycle Model Baseline Simulation and PSID Data. Dotted lines represent the PSID data, while the solid lines represent simulated paths. 

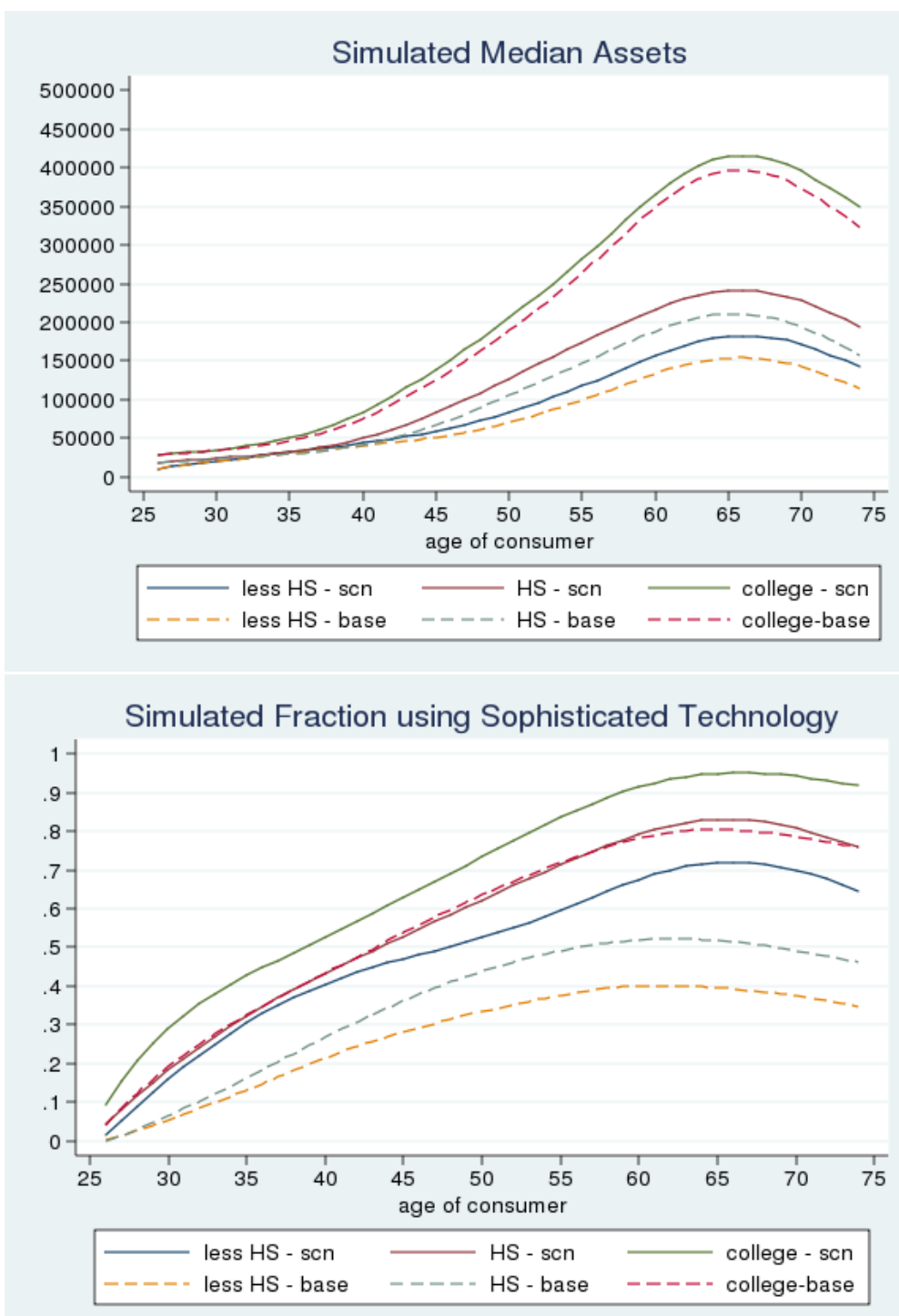

Figure 4: Impact of Full Financial Literacy on Net Assets and Percent using Sophisticated Technology by Educational Attainment Over the Lifecycle. The dotted lines represent the baseline simulations in Figure 3, while the solid lines represent the full financial literacy counterfactual. See also Table 4. 


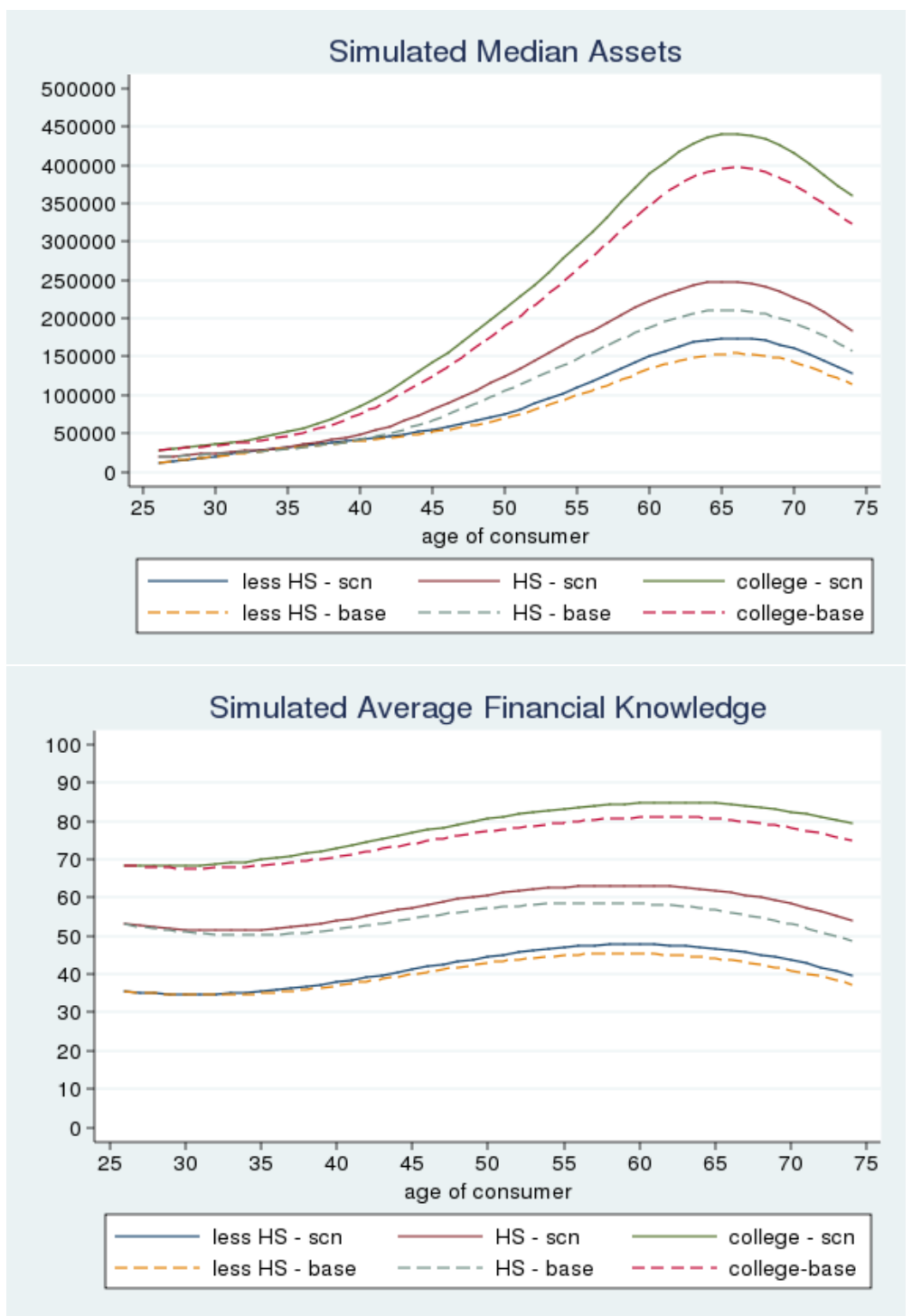

Figure 5: Impact of Lowering the Replacement Rate by $25 \%$ on Net Assets and Percent Using Sophisticated Technology by Educational Attainment over the Lifecycle. The dotted lines represent the baseline scenario in Figure 3, while the solid lines represent the counterfactual replacement rate reduction scenario. See also Table 4. 


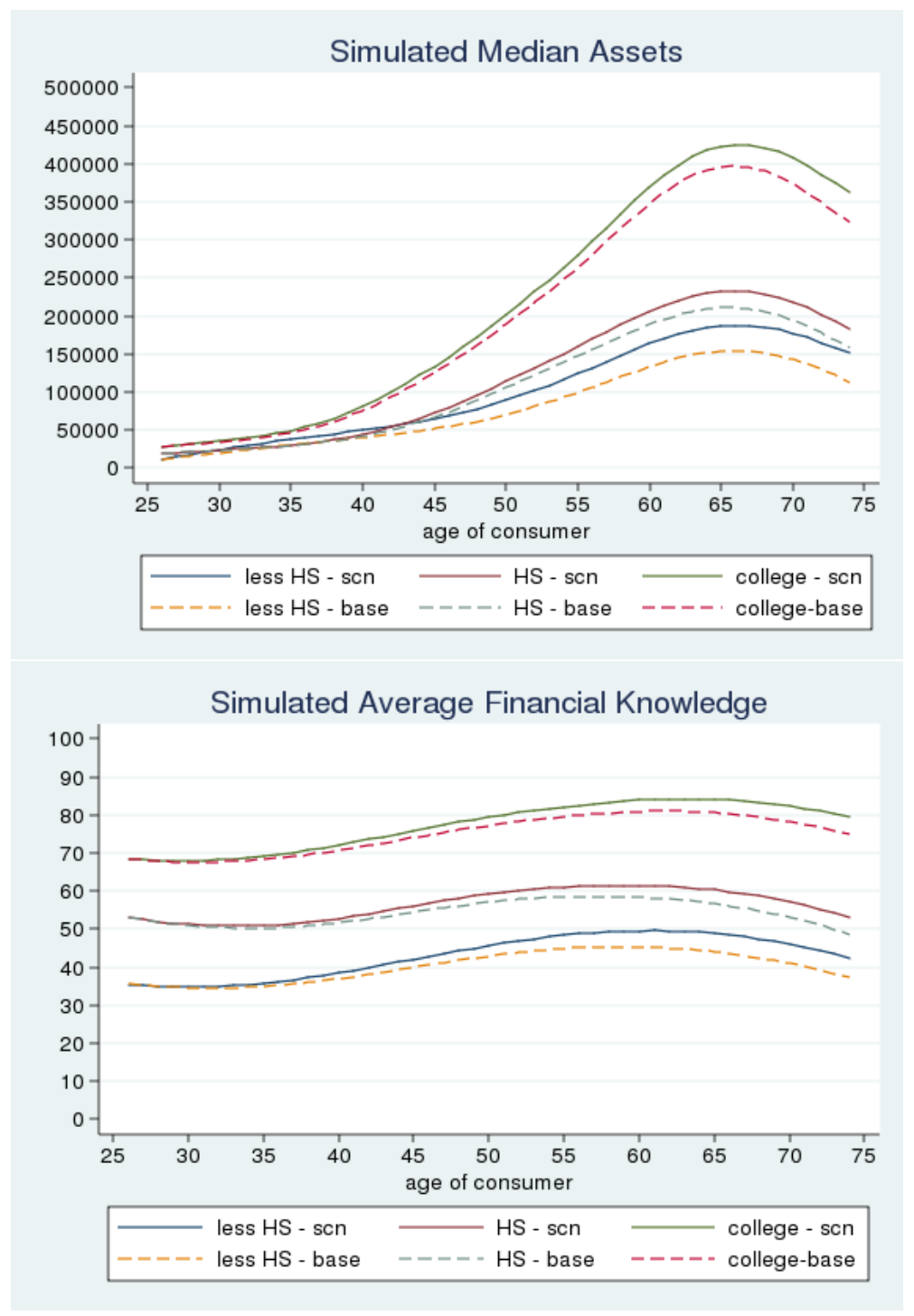

Figure 6: Effect of Lowering Means-Tested Government Transfers on Net Assets and Percent Using Sophisticated Technology by Educational Attainment, over the Lifecycle. The dotted lines represents the baseline scenario in Figure 3, while the solid lines represent the counterfactual scenario of lowering transfers. See also Table 4. 


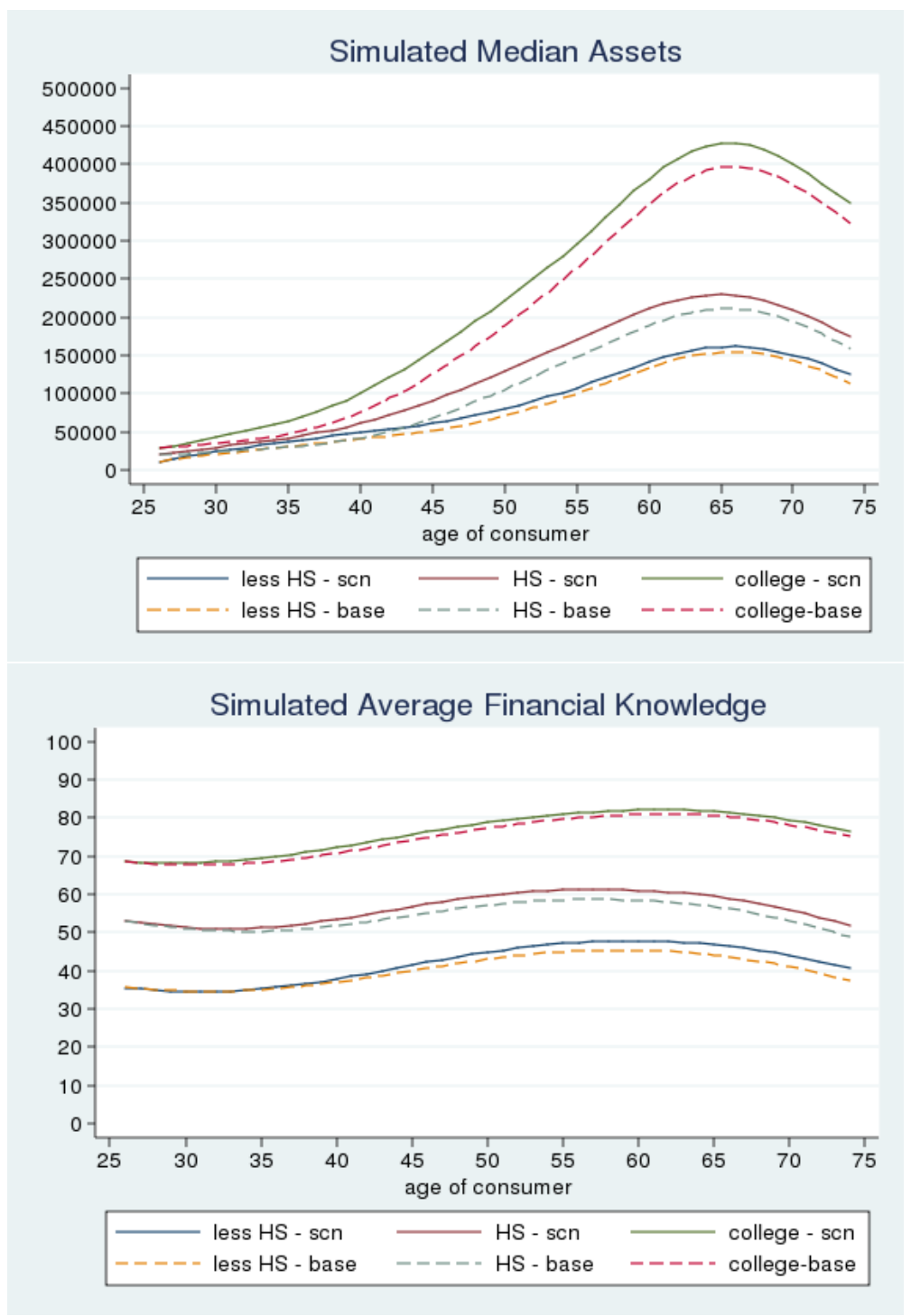

Figure 7: Effects of Increasing Income Uncertainty on Net Assets and Percent Using Sophisticated Technology by Educational Attainment, Over the Lifecycle. The dotted lines represent the baseline scenario in Figure 3, while the solid lines represent the counterfactual scenario with higher income uncertainty. See also Table 4. 


\begin{tabular}{|c|c|c|c|c|}
\hline age group & $<$ High School & High School & College + & Total \\
\hline \hline $25-35$ & 21.8 & 24.8 & 51.5 & 38.6 \\
\hline $35-45$ & 24.6 & 39.8 & 58.3 & 48.7 \\
\hline $45-55$ & 24.1 & 42.3 & 65.5 & 53.4 \\
\hline $55-65$ & 32.1 & 53.3 & 75.6 & 59.5 \\
\hline Total & 25.9 & 38.5 & 61.1 & 49.1 \\
\hline
\end{tabular}

Table 1: Lifecycle Participation (\%) in Sophisticated Financial Products (Stocks and IRAs) by Educational Attainment in the PSID 


\begin{tabular}{|c|c|c|c|}
\hline age group & $<$ High School & High School & College + \\
\hline \hline $25-35$ & 35.9 & 53.3 & 70.2 \\
\hline $35-45$ & 42.4 & 58.6 & 76.9 \\
\hline $45-55$ & 42.9 & 62.7 & 79.5 \\
\hline $55-65$ & 47.2 & 64.8 & 80.7 \\
\hline $65-75$ & 46.4 & 62.7 & 79.4 \\
\hline
\end{tabular}

Table 2: Lifecycle Fraction (\%) of Correct Answers to Financial Literacy Questions by Educational Level, from the NFCS (see text). 


\begin{tabular}{|c|c|c|c|c|}
\hline & \multicolumn{5}{|c}{$<$ High School } \\
\hline age & Median Net Worth & Mean Fin. Literacy & $\%$ Fin. Literacy $<25$ & \% Sophisticated Tech \\
\hline \hline 30 & $20,458[6,609]$ & $34.6[35.6]$ & $36.9[46.4]$ & $5.4[19.5]$ \\
\hline 40 & $40,323[28,063]$ & $36.9[42.4]$ & $36.3[31.6]$ & $21.4[21.4]$ \\
\hline 50 & $70,321[59,164]$ & $42.9[42.9]$ & $39.5[29.6]$ & $33.4[25.5]$ \\
\hline 60 & $133,632[99,095]$ & $45.3[47,3]$ & $45.2[26.2]$ & $40.1[29.9]$ \\
\hline 65 & $153,855[116,066]$ & $44.1[46.9]$ & $50.1[27.5]$ & $39.6[21.4]$ \\
\hline \hline \multicolumn{5}{|c|}{ High School } \\
\hline age & Median Net Worth & Mean Fin. Literacy & \% Fin. Literacy <25 & \% Sophisticated Tech \\
\hline \hline 30 & $23,518[20,722]$ & $51.0[53.3]$ & $15.1[20.2]$ & $6.5[23.7]$ \\
\hline 40 & $41,797[54,363]$ & $51.7[58.7]$ & $15.8[15.4]$ & $26.7[36.5]$ \\
\hline 50 & $105,373[100,256]$ & $57.1[62.8]$ & $18.5[11.9]$ & $43.8[44.0]$ \\
\hline 60 & $188,543[159,387]$ & $58.4[64.7]$ & $27.7[10.5]$ & $51.8[50.7]$ \\
\hline 65 & $211,054[190,302]$ & $56.7[63.7]$ & $34.6[11.9]$ & $51.7[55.3]$ \\
\hline \hline & \multicolumn{5}{|c|}{ College+ } \\
\hline age & Median Net Worth & Mean Fin. Literacy & $\%$ Fin. Literacy $<25$ & $\%$ Sophisticated Tech \\
\hline \hline 30 & $34,437[32,923]$ & $67.7[70.3]$ & $3.5[7.9]$ & $19.2[50.2]$ \\
\hline 40 & $75,542[108,056]$ & $70.7[76.9]$ & $2.6[3.9]$ & $43.2[57.9]$ \\
\hline 50 & $189,035[188,804]$ & $77.3[79.5]$ & $2.5[2.6]$ & $63.4[66.0]$ \\
\hline 60 & $347,896[278,018]$ & $80.9[80.7]$ & $4.7[2.9]$ & $78.1[72.5]$ \\
\hline 65 & $395,864[317,186]$ & $80.6[80.1]$ & $7.6[2.9]$ & $80.4[73.7]$ \\
\hline
\end{tabular}

Table 3: Lifecycle Net Worth, Financial Literacy, and Usage of Sophisticated Financial Technology by Educational Attainment: Simulated versus Actual Data [latter in brackets]. See text. 


\begin{tabular}{|c|c|c|c|c|c|}
\hline As of Age 65 & Baseline & Full Fin. Lit. & $\downarrow$ Repl. Rate & $\downarrow$ Cons. Floor & $\uparrow$ Income Uncert. \\
\hline \hline Median Assets & & & & & \\
\hline$<$ HS & 153,855 & 181,360 & 173,813 & 186,932 & 160,777 \\
\hline HS & 211,054 & 241,241 & 248,325 & 232,319 & 229,699 \\
\hline College+ & 395,864 & 413,742 & 440,050 & 422,622 & 427,001 \\
\hline Avg. Fin. Literacy & & & & & \\
\hline$<$ HS & 44.1 &. & 46.6 & 48.8 & 46.7 \\
\hline HS & 56.7 &. & 61.9 & 60.3 & 59.4 \\
\hline College+ & 80.6 &. & 84.6 & 84.1 & 81.7 \\
\hline \% Fin. Literacy $<25$ & & & & & 48.7 \\
\hline$<$ HS & 50.0 &. & 48.1 & 46.7 & 7.3 \\
\hline HS & 34.6 &. & 28.7 & 30.3 & \\
\hline College+ & 7.7 &. & 5.1 & 5.4 & 42.4 \\
\hline Soph. Tech. & & & & & 51.7 \\
\hline less than HS & 39.6 & 71.9 & 42.7 & 45.7 & \\
\hline HS & 51.7 & 83.0 & 59.7 & 56.6 & \\
\hline College & 80.4 & 94.9 & 86.1 & 84.6 & \\
\hline
\end{tabular}

Table 4: Net Worth, Financial Literacy, and Usage of Sophisticated Financial Technology as of Age 65 by Educational Attainment: Baseline and Four Experimental Scenarios. Baseline scenario refers to Figure 3; Full Financial Literacy scenario refers to Figure 4; $\downarrow$ Replacement Rate scenario refers to Figure 5 ; $\downarrow$ Consumption Floor scenario refers to Figure 6 ; and $\uparrow$ Income Uncertainty scenario refers to Figure 7. See text. 